\title{
ESTUDO E APLICAÇÃO DE UM MÉTODO DE ANCORAGEM ENTRE BAMBU E CONCRETO PARA LAJE COM ADIÇÃO DE PET E BAMBU
}

\section{STUDY AND APPLICATION OF AN ANCORAGING METHOD BETWEEN BAMBOO AND CONCRETE FOR SLAB WITH ADDITION OF PET AND BAMBOO}

\author{
Camila R. Silveira ${ }^{1}$, Vinicius da Fonseca ${ }^{1}$, Willyam A. Vieira ${ }^{1}$, Daniele \\ Araujo Altran ${ }^{2}$, Filipe Bittencourt Figueiredo ${ }^{2}$, Larissa Queiroz Minillo ${ }^{1}$ \\ ${ }^{1}$ Universidade do Oeste Paulista - UNOESTE, Curso de Engenharia Civil \\ E-mail: camila_r_silveira@hotmail.com; viniciusfonsecaeng@gmail.com; \\ willyamandrade@hotmail.com; larissaminillo@gmail.com
${ }^{2}$ Universidade Federal da Grande Dourados - UFGD, Departamento de Engenharia Civil
E-mail: danielearaujoaltran@gmail.com; filipefigueiredo@ufgd.edu.br

RESUMO - A ancoragem da armadura no concreto é fundamental para que os elementos trabalhem em conjunto, possibilitando a transferência integral dos esforços solicitantes, o que significa que não deve ocorrer escorregamento entre o concreto e sua armação. Este estudo visa aplicar métodos eficientes para o aumento de ancoragem e aderência entre bambu e concreto. Baseado na ABNT NBR 6118:2014, desenvolveram-se três tipos de lajes e aplicaram-se diferentes intervenções físicas no bambu para o aumento de ancoragem e aderência entre bambu e concreto. Os protótipos foram submetidos a ensaios de consistência e de resistência a compressão no concreto utilizado, regido pela ABNT NBR NM 67:1998 e ABNT NBR 5739:2007, respectivamente. Os resultados viabilizaram a utilização dos elementos adicionais, tendo as lajes com aplicação das técnicas de ancoragem e aderência, a resistência mecânica superior a de uma laje maciça convencional desenvolvida nos mesmos padrões, indicando viabilidade quanto à aplicação de ambos os métodos.

Palavras-chave: Ancoragem. Aderência. Bambu. Laje. PET.

Recebido em: $10 / 08 / 2018$ Revisado em: 06/09/2018 Aprovado em: 10/09/2018
ABSTRACT - The anchoring of reinforcement in concrete is fundamental for the elements to work together, enabling the full transfer of the applicant efforts, this means that there should be no slip between the concrete and its reinforcement. This study aimed to apply an efficient method to increase anchorage and adherence between bamboo and concrete. Based on ABNT NBR 6118:2014, has developed three slabs type and different physical interventions were applied in the bamboo to increase anchorage and adherence between bamboo and concrete. The prototypes were submitted to slump tests and compressive strength tests on the concrete used, controlled by the ABNT NBR NM 67:1998 
and ABNT NBR 5739:2007, respectively. The results enabled the use of the additional elements, being the slabs with application of the anchorage and adherence techniques, the superior mechanical resistance of a conventional solid slab developed in the same standards, indicating feasibility for the application of both methods.

Keywords: Anchoring. Adherence. Bamboo. Slab. PET. 


\section{INTRODUÇÃO}

A busca por novos métodos e materiais que unidos ao concreto podem formar uma estrutura sólida e resistente orientam os atuais estudos de estruturas de concreto armado.

Dentre os materiais estudados estão o bambu, com função estrutural, e a garrafa PET, como enchimento. Assim, com a finalidade de viabilizar a utilização do bambu e do PET dentro de uma laje de concreto se fez necessária a análise do desempenho de uma estrutura de concreto e bambu.

A união entre o aço e concreto, formando o concreto armado tem como base fundamental a aderência, podendo esta ser por adesão, por atrito ou até mesmo por aderência mecânica. Estudos como os de Leonhardt e Mönnig (1977), demonstram que até mesmo barras de aço lisas possuem pequenos denteamentos em sua superfície, gerando uma aderência ainda que pequena se comparada com as barras de aço confeccionadas com nervuras. A aderência, portanto, leva ao conceito de ancoragem.

A ancoragem é para concreto armado, segundo Muzardo, Pinheiro e Souza (2003), a fixação da barra de aço ao concreto, a fim de que estes mantenham-se fixos quando submetidos a esforços. Da mesma maneira, a ancoragem deve existir entre o bambu e o concreto para que os dois materiais trabalhem juntos e sejam caracterizados como estrutura.

A ocorrência da falha de aderência e ancoragem entre bambu e concreto, dificulta a comparação com o aço neste quesito, tendo em vista que "[...] a tensão de aderência de cálculo entre o bambu e o concreto é apenas $20 \%$ inferior à tensão de aderência entre o aço liso e o concreto", segundo Mesquita et al. (2006). Entretanto, pesquisadores sugerem tratamentos para aumentar a aderência entre bambu e concreto. Mesquita et al. (2006) constatou que o cravamento de pinos de madeira e aço no bambu pode aumentar em 50 e $80 \%$, respectivamente, a sua aderência com o concreto. Outros tratamentos já estudados, conforme Ferreira (2002) apud Oliveira e Vito (2012), são:

- Bambu a milanesa, que é a aplicação de piche chapiscado com areia, tornando a superfície rugosa e por ter a aplicação do piche funciona também como impermeabilizante;

- Colocação de arame farpado pregado sobre o colmo ou talisca;

- Cravamentos de grampos de cerca sobre o bambu;

- Ranhuras realizadas na casca das talisca;

Segundo Cardoso (2000 apud SOUZA; VESPA; ARAUJO, 2009), para que o bambu não absorva a água do concreto, quando for utilizado seco, é necessário deixá-lo três dias antes da concretagem submerso em água. Ghavami (1995 e Lopes et al. 2002 apud MESQUITA et al. 2006) explicam que quando o bambu absorve a água do concreto e seca, variando então o seu volume, há interferência de forma negativa na aderência entre os dois materiais.

Desta forma, visando uma construção sustentável e que reutilize material reciclável, estuda-se a utilização da garrafa PET e do bambu na laje de concreto armado. A PET com função de preenchimento de espaço e consequente diminuição do peso próprio da estrutura, diminuindo a quantidade de concreto, e o bambu com a função de travamento das garrafas e a substituição da armadura de aço, sendo este aderido corretamente ao concreto.

\section{METODOLOGIA}

O estudo decorreu-se da análise de três tipos diferentes de lajes, sendo uma laje maciça convencional que serviu como base para as comparações, e duas lajes com adição de garrafa PET e bambu. As malhas de bambu receberam a aplicação da mesma técnica para aumento de ancoragem, e 
técnicas distintas para aumento de aderência, com o intuito de averiguar o método de aderência mais viável em relação à resistência mecânica.

Para o sistema de ancoragem chanfrou-se as extremidades das barras, formando duas cavidades em cada ponta, como ilustra a Figura 1 . O método foi escolhido em função da rigidez do bambu, ou seja, o mesmo ser incompatível com técnicas de dobras, como o aço.

Figura 1. llustração do sistema de ancoragem entre bambu e concreto

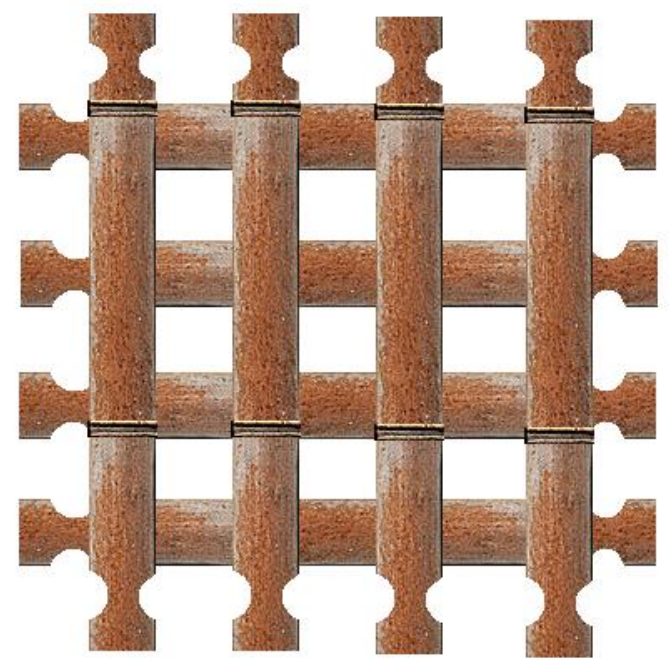

Para o aumento da aderência entre bambu e concreto utilizaram-se dois dos métodos citados por Ferreira (2002), bambu enrolado com arame farpado (Figura 2) e ranhuras nas faces (Figura 3), semelhantes aos sucos das barras de aço.

Figura 2. Técnica do bambu enrolado com arame farpado

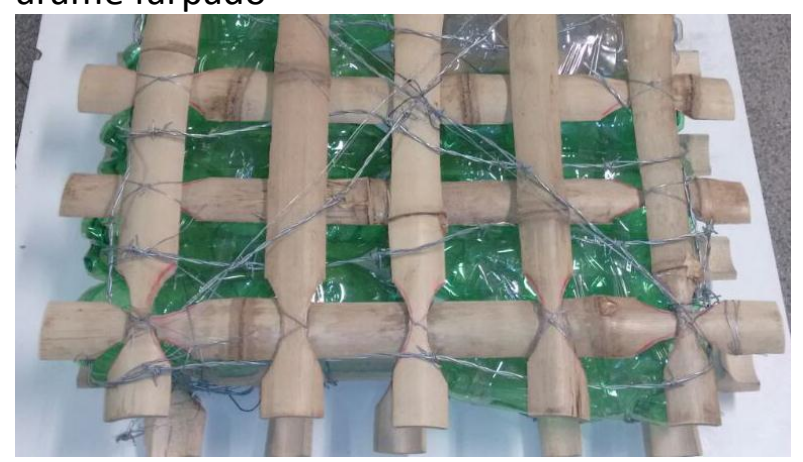

Figura 3. Técnica das ranhuras nas faces do bambu

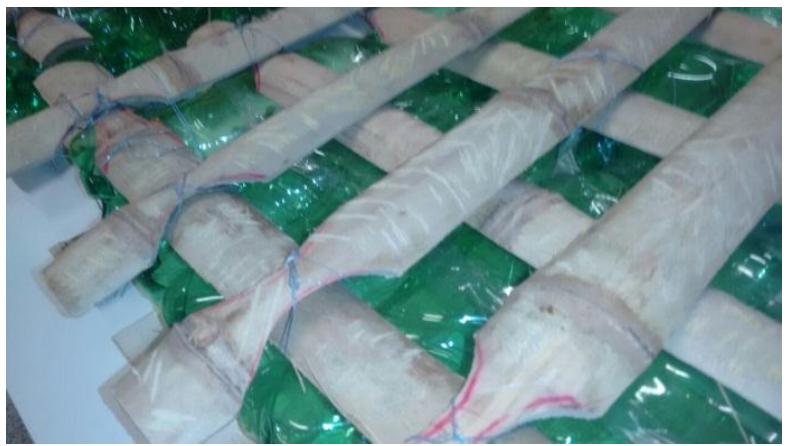

\subsection{Coleta e preparação dos materiais}

A princípio, coletaram-se bambus da espécie Bambusa Vulgaris na região de Presidente Prudente - SP, os mesmos apresentavam comprimento aproximado de 4 metros e diâmetro externo e interno médio de $10 \mathrm{~cm}$ e $7 \mathrm{~cm}$, respectivamente. Após a coleta, os bambus permaneceram em repouso para a correta desidratação por 15 dias, conforme Ghavami e Barbosa (2007 apud OLIVEIRA, 2013), e posteriormente foram cortados em barras de $69 \mathrm{~cm}$ e um quarto da seção transversal.

As garrafas PET foram coletadas em uma empresa de refrigerantes em Presidente Prudente - SP, provenientes do refugo, estas foram fixadas com fita adesiva em conjuntos de seis unidades, e o furo vedado.

Para a confecção do concreto utilizouse o traço de 1:3:2 (cimento: areia: brita), e fator água cimento de 0,7. Realizou-se em cada concretagem ensaios de consistência (slump test) e de resistência a compressão no concreto utilizado, regidos pela ABNT NBR NM 67:1998 e ABNT NBR 5739:2007, respectivamente.

Para a confecção da laje com armação total em aço, cortou-se a malha de aço de 4,2 $\mathrm{mm}$ de bitola, nas dimensões $75 \mathrm{~cm} \times 75 \mathrm{~cm}$, e dobraram-se as pontas $3 \mathrm{~cm}$ em 135으, para a correta ancoragem no concreto, restando portanto, duas armaduras de $69 \mathrm{~cm} \times 69 \mathrm{~cm}$, espaçadas em $10 \mathrm{~cm}$, e um afastamento entre as malhas e as faces da laje de $2 \mathrm{~cm}$, para a capa de concreto como estabelecido pela ABNT NBR 6118:2014. Como afastadores utilizou-se aço de mesma bitola cortado nas 
dimensões especificadas, conforme a Figura 4.

Figura 4. Armaduras positiva e negativa com os respectivos espaçamentos

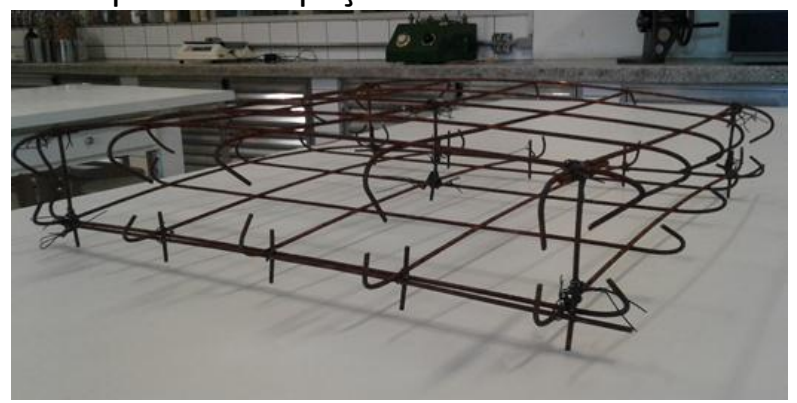

$\mathrm{Na}$ confecção da armadura em bambu, as barras foram unidas com arame recozido em forma de malha, respeitando o mesmo número de barras de aço utilizado na laje maciça convencional. Deixou-se assim, as quatro malhas de bambu produzidas submersa em um tanque com água por 72 horas, para que o bambu não absorvesse a água de amassamento do concreto, conforme Cardoso (2000 apud SOUZA; VESPA; ARAUJO, 2009). Por fim, aplicaram-se as intervenções físicas no bambu para aumento de ancoragem e aderência e fez-se a junção das malhas utilizando a garrafa PET como elemento de preenchimento e separador, visto que esta apresenta $10 \mathrm{~cm}$ de espessura.

\subsection{Ensaio de resistência da laje}

Como método de ensaio para obtenção dos resultados das resistências das lajes baseou-se no princípio da Lei da Alavanca desenvolvido por Arquimedes, que consiste na aplicação de uma força $P$ no braço maior (b), sendo possível equilibrar uma força maior, $R$, que esteja na ponta do braço menor (a), já que o produto $P \times$ b é igual ao produto $R \times$ a, ou seja, o procedimento está diretamente relacionado ao momento fletor, visto que ocorre o produto da força e da distância até o apoio (ASSIS, 2008). Baseado nesse princípio utilizou-se a mesa de reação do laboratório de construção civil da UNOESTE, para o ensaio de resistência da laje após os 28 dias de cura. A mesa é composta por uma viga alavanca que têm por função transferir as cargas de uma extremidade para a outra, na qual a mesma foi apoiada sobre placas, e esse conjunto apoiado sobre a parte central da laje, que também foi apoiada, entretanto, apenas em dois dos lados. O sistema de ruptura foi reproduzido conforme a Figura 5.

Figura 5. Método de ensaio das lajes

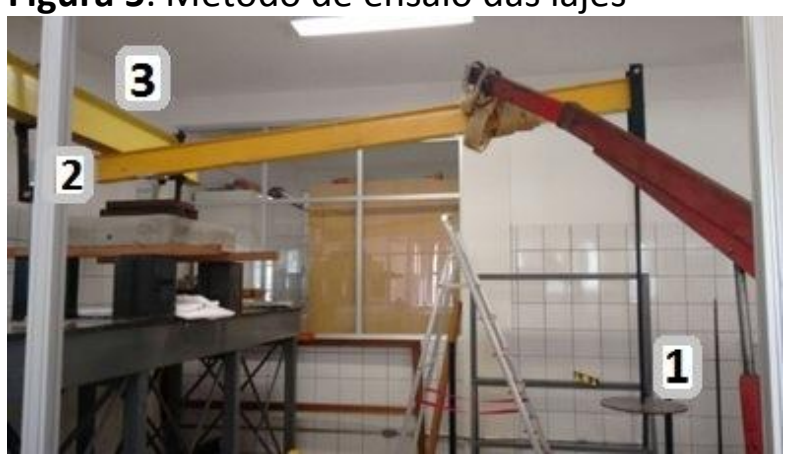

A viga de transferência de cargas é submetida a pesos em sua extremidade direita (1), onde os pesos geram esforços na extremidade esquerda (2), provocando uma força de momento fletor na viga, agindo assim como uma alavanca, pois a viga de perfil I (3), que está sobre a viga de transferência, impede o movimento da mesma, deixando-a estável e provocando uma reação contrária que força a laje, até o seu rompimento. A transferência de carga entre o perfil metálico e a laje se da através de placas metálicas, conforme a Figura 6 .

Figura 6. Placas de transferência de cargas entre o perfil metálico e a laje

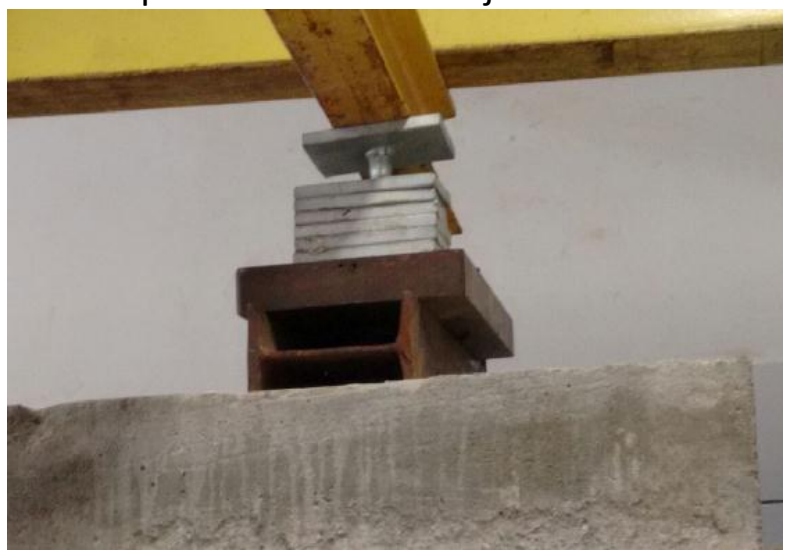

Para o cálculo das tensões suportadas pelas lajes, aferiram-se as massas das placas de transferência de cargas e os demais 
elementos utilizados no ensaio, estas foram dispostas conforme a Tabela 1.

Tabela 1. Massas das peças utilizadas no ensaio

\begin{tabular}{|c|c|c|c|}
\hline Elementos & $\begin{array}{c}\text { Massa } \\
\mathbf{( k g )}\end{array}$ & Elementos & $\begin{array}{c}\text { Massa } \\
\mathbf{( k g})\end{array}$ \\
\hline $\begin{array}{c}\text { Viga } \\
\text { alavanca }\end{array}$ & 56,60 & $\begin{array}{c}\text { Suporte dos } \\
\text { pesos }\end{array}$ & 16,00 \\
\hline Peso 1 & 2,00 & $\begin{array}{c}\text { Placa de } \\
\text { transferência }\end{array}$ & 8,75 \\
\hline Peso 2 & 4,00 & $\begin{array}{c}\text { Placa de aço } \\
\text { maior }\end{array}$ & 27,88 \\
\hline Peso 3 & 5,00 & $\begin{array}{c}\text { Placa de aço } \\
\text { menor }\end{array}$ & 1,51 \\
\hline Peso 4 & 8,00 & $\begin{array}{c}\text { Placa com } \\
\text { pino 1 }\end{array}$ & 1,59 \\
\hline Peso 5 & 10,00 & $\begin{array}{c}\text { Placa com } \\
\text { pino 2 }\end{array}$ & 1,34 \\
\hline Peso 6 & 15,00 & $\begin{array}{c}\text { Placa de aço } \\
\text { (calço 1) }\end{array}$ & 0,23 \\
\hline Peso 7 & 20,00 & $\begin{array}{c}\text { Placa de aço } \\
\text { (calço 2) }\end{array}$ & 1,23 \\
\hline
\end{tabular}

Primeiramente, calcularam-se as cargas correspondentes a quantidade de massa na extremidade direita da viga alavanca, assim como o peso próprio da mesma. Através dos referidos dados, representou-se para cada laje o diagrama de corpo livre no software Ftool, conforme a Figura 7, referente a laje maciça convencional.

Figura 7. Diagrama de corpo livre da viga alavanca na laje maciça convencional

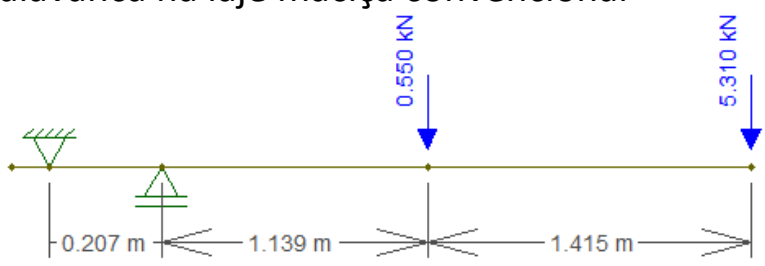

Obtiveram-se através do diagrama de corpo livre as reações de apoio da viga alavanca, em função das cargas aplicadas na mesma, como indicado na Figura 8.
Figura 8. Reações de apoio da viga alavanca na laje convencional

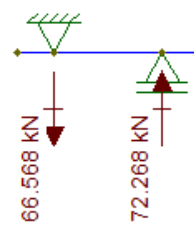

Por fim, para o cálculo da tensão, relacionou-se a reação de apoio referente à carga suportada pela laje com a área de contato da placa de transferência das cargas, conforme a Equação 1.

$$
\text { Tensão }=\frac{C \arg a(\text { total })}{\text { Área }(\text { contato })} \quad \text { (equação 1) }
$$

\section{RESULTADOS}

\subsection{Ensaio de resistência à compressão do concreto}

Os 8 corpos de prova foram rompidos com idades de 7, 14, 21 e 28 dias, sendo quatro corpos de prova referentes a primeira etapa de concretagem e os quatro restantes, referentes a segunda etapa, cujo os 
resultados obtidos foram representados na Tabela 2.

Tabela 2. Resistências à compressão dos corpos de prova

\begin{tabular}{|c|c|c|}
\hline $\begin{array}{c}\text { Tempo } \\
\text { de cura } \\
\text { (dias) }\end{array}$ & $\begin{array}{c}\text { Fck da primeira } \\
\text { concretagem } \\
\text { (MPa) }\end{array}$ & $\begin{array}{c}\text { Fck da } \\
\text { segunda } \\
\text { concretagem } \\
\text { (MPa) }\end{array}$ \\
\hline 7 & 6,90 & 6,40 \\
\hline 14 & 11,00 & 12,10 \\
\hline 21 & 16,90 & 16,30 \\
\hline 28 & 19,30 & 21,00 \\
\hline $\begin{array}{c}\text { Média do } \\
\text { fck de 28 } \\
\text { dias } \\
\text { (MPa) }\end{array}$ & \multicolumn{2}{|c|}{20,15} \\
\hline
\end{tabular}

\subsection{Ensaio de consistência do concreto}

Os resultados do teste de consistência (slump test) foram de $16,5 \mathrm{~cm}$ e $18 \mathrm{~cm}$, para a primeira e para a segunda etapa de concretagem, respectivamente.

\subsection{Ensaio de resistência das lajes}

Os resultados das resistências da laje maciça convencional e dos dois modelos com técnicas de ancoragem e aderência estão representados conforme o Gráfico.

Gráfico. Resistências das lajes rompidas aos 28 dias (MPa)

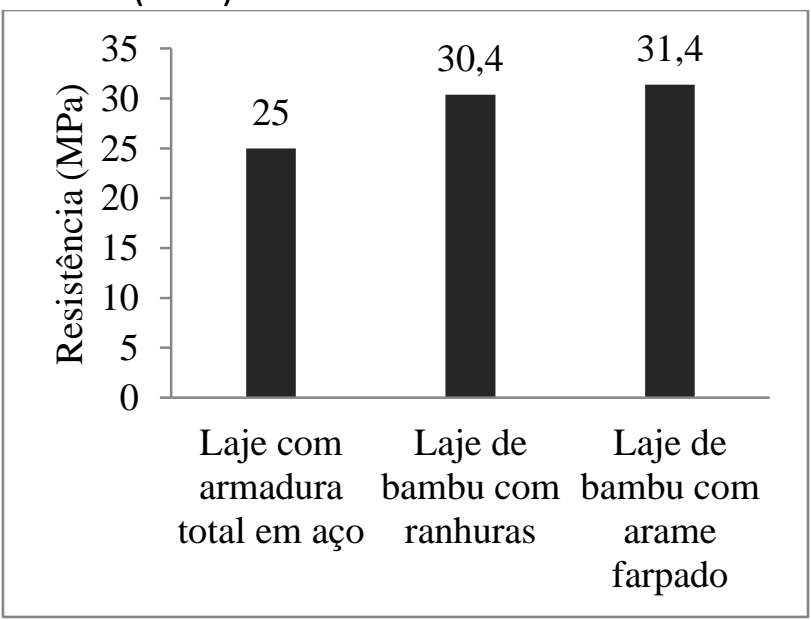

\section{DISCUSSÃO DOS RESULTADOS}

As resistências obtidas a partir do ensaio de compressão nos corpos de prova, referentes a cada etapa de concretagem, não indicam discrepância de valores, tendo em vista que obteve-se uma resistência média igual a 20,15 $\mathrm{MPa}$, mantendo-se acima do valor estipulado na ABNT NBR 6118:2014 de $20 \mathrm{MPa}$ para concreto estrutural.

O teste de consistência (slump test) revelou valores próximos entre as duas concretagens, sendo $16 \mathrm{~cm}$ o valor mínimo, referente à primeira concretagem, e 18,50 $\mathrm{cm}$ o valor máximo, referente à segunda concretagem, indicando uma boa consistência para a finalidade aplicada, e uma discrepância de $1,5 \mathrm{~cm}$ entre os valores mínimo e máximo. Os resultados estão diretamente relacionados com 0 fator água/cimento utilizado.

Por fim, as resistências mecânicas das lajes com armadura em bambu assemelharam-se, sendo 30,4 MPa a laje com ranhuras e 31,4 $\mathrm{MPa}$ a laje com arame farpado. Entretanto, quando comparadas à resistência da laje maciça convencional, que foi de $25 \mathrm{MPa}$, notou-se uma diferença relevante, sendo possível observar que a laje com a técnica das ranhuras a superou em $17,76 \%$, e a laje com a técnica do arame farpado excedeu-a em 20,38 \%.

\section{CONCLUSÕES}

O estudo indicou que as lajes com adição de garrafas PET com função de preenchimento e o bambu com a aplicação das técnicas para aumento de ancoragem e aderência, tiveram ambas a resistência mecânica superior a do protótipo convencional, indicando eficiência nos sistema de ancoragem desenvolvido, sendo o bambu com arame farpado o método mais eficiente de aderência quanto à resistência mecânica, entretanto quanto ao custo, o método das ranhuras na superfície é o mais viável, ao passo que esta intervenção não requer a aplicação de outros materiais. 
Sugere-se para futuros trabalhos, estudos relacionados à degradação do bambu em função do tempo, haja vista que este é um material orgânico que pode perder suas características de reforço em decorrência de possível deterioração, bem como o estudo de outros processos de ancoragem, como a fixação de pinos metálicos nas extremidades da barra de bambu.

\section{REFERÊNCIAS}

ASSIS, A. K. T. Arquimedes, o Centro de Gravidade e a Lei da Alavanca. 1 ed. Montreal, Canadá: Apeiron Montreal, 2008.

ASSOCIAÇÃO BRASILEIRA DE NORMAS TÉCNICAS. Concreto - Determinação da consistência pelo abatimento do tronco de cone: NBR NM 67. Rio de Janeiro: ABNT, 1998.

ASSOCIAÇÃO BRASILEIRA DE NORMAS TÉCNICAS. Concreto- Ensaio de compressão de corpos-de-prova cilíndricos: NBR 5739. Rio de Janeiro: ABNT, 2007.

ASSOCIAÇÃO BRASILEIRA DE NORMAS TÉCNICAS. Projeto de estruturas de concreto - Procedimento: NBR 6118. Rio de Janeiro: ABNT, 2014.

FERREIRA, G. C. S. Vigas de concreto armadas com bambu. 2002. $264 \mathrm{f}$. Dissertação (Mestrado em Edificações) Universidade Estadual de Campinas, São Paulo, 2002.

LEONHARDT, F.; MÖNNIG, E. Construções de concreto: Princípios básicos do dimensionamento de estruturas de concreto armado. 1.ed. Rio de Janeiro: Interciência, 1977. v.1.

MESQUITA, L. P> et al. Determinação da tensão de aderência do bambu-concreto. Revista Brasileira de Engenharia Agrícola e Ambiental, Campina Grande, v.10, n.2, p.
505-5016, 2006. Disponível em: http://www.scielo.br/pdf/rbeaa/v10n2/v10n 2a36.pdf. Acesso em: 6 abr. 2017.

MUZARDO, C.; PINHEIRO, L.; SANTOS, S. Lajes maciças.. São Carlos. 2003. 29p. (Notas de aula).

OLIVEIRA, C.; VITO, M. Substituição total do aço, usando bambu como armadura de combate a flexão em vigas de concreto. Artigo submetido ao Curso de Engenharia Civil da UNESC (Universidade do Extremo Sul Catarinense), 12p. 2012.

OLIVEIRA, L. F. A. Conhecendo Bambus e suas potencialidades para uso na construção civil. Monografia apresentada ao Curso de Especialização em Construção Civil, Universidade Federal de Minas Gerais. Belo Horizonte, MG. 90p. 2013.

SOUZA, L.; VESPA, T.; ARAUJO, M. Lajes com armadura de bambu: um estudo comparativo com as lajes convencionais de aço. In: ENCONTRO INTERNACIONAL DE PRODUÇÃO CIENTÍFICA CESUMAR. 2009. Maringá. Anais [...]. Maringá, PR: Centro Universitário de Maringá, 2009. Disponível em: https://www.unicesumar.edu.br/epcc2009/wpcontent/uploads/sites/77/2016/07/lucimeire _brenzan_zampar_souza.pdf. Acesso em: 20 mar. 2017. 